\title{
AVALIAÇÃO DO CONHECIMENTO DOS ESTUDANTES DO PRIMEIRO PERÍODO DE MEDICINA VETERINÁRIA DA FACULDADE DE CIÊNCIAS AGRÁRIAS E VETERINÁRIAS - UNESP, CÂMPUS JABOTICABAL SOBRE O PAPEL DO MÉDICO VETERINÁRIO NA SAÚDE PÚBLICA
}

\author{
EVALUATION OF THE FIRST GRADE STUDENTS OF VETERINARY MEDICINE OF \\ THE COLLEGE UNESP - CAMPI JABOTICABAL, ABOUT THE ROLE OF THE \\ VETERINARIAN IN THE PUBLIC HEALTH
}

\author{
J. H. BEGALI ${ }^{1}$, C. R. BASTOS ${ }^{1}$, M. A. PICINATO ${ }^{1}$, A. P. R. GRISÓLIO ${ }^{1}$, P. E. CARRARO ${ }^{1}$, \\ F. O. BARBOSA ${ }^{1}$, A. A. B. CARVALHO ${ }^{2}$
}

\section{RESUMO}

A saúde pública veterinária tem a finalidade de proteger e promover a saúde humana. Por meio da Portaria 2488 de outubro de 2011 o médico veterinário foi incluído no grupo de profissionais que podem compor o Núcleo de Apoio à Saúde da Família (NASF). No entanto, para que esse profissional atue em sua plenitude é necessário que conheça sua importância para a população, exercitando os conhecimentos em saúde coletiva além de contribuir no processo melhoria da saúde. Com intuito de avaliar o grau de conhecimento dos alunos, foi aplicado um questionário para o primeiro período de medicina veterinária da UNESP Câmpus Jaboticabal, totalizando 38 alunos, com perguntas fechadas abordando conceitos sobre a participação do médico veterinário no Sistema Único de Saúde (SUS) e sua importância na saúde humana, Estratégia Saúde da Família (ESF) e NASF. Logo após, ofereceu-se uma palestra abordando as atividades exercidas pelo médico veterinário na saúde pública veterinária, com a expectativa que os estudantes entrem com a consciência da sua importância neste cenário. Apenas $2 \%(1)$ conhecia o significado de ESF e NASF; 5\%(2) dos alunos conheciam qual o nível de atenção a ESF e o NASF são classificados. Com relação a participação do médico veterinário no Sistema Único de Saúde (SUS) e Programa Saúde da Família (PSF), antes da palestra 25\%(10) responderam ter conhecimento e todos os participantes afirmaram que o médico veterinário pode trabalhar com saúde pública humana e que existe relação entre a medicina veterinária e políticas públicas de saúde. Por meio do resultado obtido na avaliação, conclui-se que há necessidade de capacitar os alunos da graduação em medicina veterinária quanto aos temas relacionados. A palestra colaborou quanto a finalidade de informação e aprendizagem. A conscientização da inserção do médico veterinário no NASF é fundamental para o conhecimento sobre sua atuação na saúde pública veterinária.

PALAVRAS-CHAVE: MÉDICO VETERINÁRIO. NÚCLEO DE APOIO À SAÚDE DA FAMÍLIA. SAÚDE PÚBLICA VETERINÁRIA.

AGRADECIMENTOS: CAPES

ÁREA TEMÁTICA: Saúde Pública 